\title{
Opportunities and Challenges of Economic Development in Malaysia's Rural Areas
}

\author{
ELLFRELSTERN ANAK EDIRIN*
}

\author{
Faculty of Social Sciences and Humanities, Universiti Malaysia Sarawak, 94300 Kota Samarahan, Sarawak, \\ Malaysia \\ *Corresponding author: ellfrelstern@gmail.com
}

\begin{abstract}
Rural areas play traditionally important role for our economy as well maintaining social stability. Most of the development is entirely dependent on natural resources in the area which is specialized in a limited number of industries such as agriculture, livestock, forestry, fisheries and local tourism. People that live in rural areas have fewer choices in the social and economic terms. They are facing many problems such as low income, unemployment, low quality of social services like education and healthcare. In addition, remoteness from major urban centres is also one of the problems which is implying the need for well-developed transport infrastructure to support economic development. As stated in the Eleventh Malaysia Plan, the Malaysian Government is committed to ensuring equitable opportunities for all segments of society.
\end{abstract}

Keywords: Development, economic, Eleventh Malaysia Plan, rural

Copyright: This is an open access article distributed under the terms of the CC-BY-NC-SA (Creative Commons Attribution Non Commercial Share Alike 4.0 International License) which permits unrestricted use, distribution, and reproduction in any medium, for non-commercial purposes, provided the original work of the author(s) is properly cited.

\section{INTRODUCTION}

Rural areas cover a variety of agricultural lands, forests, and small industries. These areas have large natural, cultural and historic resources that can be the basis for economic development. Compared with urban residents, people that live in rural areas have fewer choices in the social and economic terms. They are facing many problems such as low income, unemployment, low quality of social services like education and healthcare. In addition, remoteness from major urban centres is also one of the problems which is implying the need for well-developed transport infrastructure to support economic development (Surchev, 2009).

Rural areas can be classified according to different criteria. Indicators of demographic, administrative, infrastructural and social development of the region can be divided into two groups. First is about the general criteria which include geographical location, size, number of inhabitants, population density, remoteness from urban centres and indicators characterizing the natural conditions of the area. The second group of criteria includes indicators which report socio-economic problems of the regions (rural area) which is employment, age structure, migration, depopulation, level of infrastructure development, development of agricultural and non- agricultural sector, gross added value per capita, average wage and environmental protection. The most common indicators in this group can be summarized as economic, social and socio economic (Surchev, 2009).

The definition of rural has been in dispute for decades. Many different definitions of the rural have been given, each focusing on a different specialized aspect which is in turn, statistical, administrative, built up area, functional regions, agricultural and population density. Historically, traditional agriculture supplied both employment and income in rural areas. However, in today's developed countries the concept of rurality should not be confused with that of an agricultural economy as stated by De Gennaro and Fantini (n.d.).

\section{MATERIALS \& METHODS}

As stated in the Eleventh Malaysia Plan, the Malaysian Government is committed to ensuring equitable opportunities for all segments of society, in particular the B40 households (referring to the bottom of 40 percent of households with monthly income of RM 3900 and below). All Malaysians, and in particular vulnerable groups 
will benefit from better access to quality education and training, efficient infrastructure and social amenities, better employment and entrepreneurial opportunities, as well as wealth ownership. Rural areas will be transformed with improved connectivity, mobility, and a conducive business environment. All households will witness an increase in income, and the B40 households will be elevated towards a middle-class society. The status of the Bumiputera economic community will be further enhanced (Economic Planning Unit, 2015).

All B40 households regardless of ethnicity will be given greater focus, especially the urban and rural poor, lowincome households, as well as the vulnerable and inspirational households. The size and composition of middleclass society will grow to $45 \%$ by 2020 . The mean income of the B40 households will double to RM5,270 in 2020 from RM2,537 in 2014. More B40 households will have family members with tertiary education, from $9 \%$ in 2014 to $20 \%$ in 2020. The income share of the B40 to national household income will also increase from $16.5 \%$ in 2014 to $20 \%$ in 2020 (Economic Planning Unit, 2015).

Besides, the government is committed in transforming the public service by becoming more citizen-centric and enhancing the productivity, efficiency, and effectiveness of service delivery. The aspiration is to deliver public service in a less bureaucratic, hierarchical, and centralised manner which is with talent that is multiskilled and a range of service offerings that is more accessible and innovative. To achieve these outcomes, the Government has identified five focus areas:

- Enhancing service delivery with citizens at the centre by eliminating unnecessary bureaucratic processes, expanding the outreach of its services, and increasing accountability

- Rationalising public sector institutions for greater productivity and performance by reducing overlapping roles and functions among agencies, right sizing the public service, and introducing an exit policy for underperformers

- Strengthening talent management for the public service of the future by providing a more conducive working environment including flexible work arrangements, empowering ministries and agencies, and upgrading public sector training

- Enhancing project management for better and faster results by improving the process of project selection and resource allocation, establishing dedicated project implementation teams, and creating a pool of professional project management personnel; and

- Capitalising on local government for quality services at the local level through greater engagement with local community and NGOs, expanding the outreach and quality of service, and further empowering local authorities in terms of capacity and capability.

(Economic Planning Unit, 2015)

\section{RESULTS \& DISCUSSION}

During the Tenth Malaysia Plan, 2011-2015, inclusivity was a key strategy towards achieving a prosperous and equitable society. Targeted implementation of development and empowerment programmes resulted in an increase in the socio-economic status of Malaysians. Overall income distribution improved, with the Gini coefficient reducing from 0.441 in 2009 to 0.401 in 2014, exceeding the 2015 target of 0.420 . Mean monthly household income of the bottom 40\% households income group (B40 households) increased to RM2,537 in 2014 from $\mathrm{RM1,440}$ in 2009. The provision of rural basic infrastructure combined with entrepreneur development activities has enabled people in rural and remote areas to increase their participation in socio-economic development. Focused development in regional economic corridors has also attracted investment and created jobs for locals, especially in less developed areas. Despite these achievements, more needs to be done to ensure that fruits of development are enjoyed and benefit all communities (Economic Planning Unit, 2015).

Addressing the needs of special target groups, such as the Orang Asli in Peninsular Malaysia and those living in rural and remote areas in Sabah and Sarawak, were addressed through land development and ownership, as well as skills training programmes. A total of 32,561 hectares of Native Customary Rights (NCR) land were gazetted for Orang Asli in Peninsular Malaysia, 26,956 hectares for Bumiputera in Sabah, and 558,571 hectares for Bumiputera in Sarawak. The number of Orang Asli receiving skills training increased from 435 in 2011 to 3,750 in 2014, while 2,100 Bumiputera in Sabah and Sarawak also benefited from various skills training programmes. In addition, a total of 4,446 Chinese new village residents were assisted through the Special Financial Loan Scheme for New Village Residents. Total loans provided as of 2014 were worth RM142 million (Economic Planning Unit, 2015).

So now we move a little bit to Sarawak in general. Significant progress has been made in rural basic infrastructure delivery for Sabah and Sarawak to increase the participation of Person with disabilities (PWD) in economic activities; the Government introduced employment support services for PWD including the Job Coach Programme. 
In line with the policy allocating $1 \%$ of jobs opportunities in the public sector for PWD, $0.2 \%$ of total public servants in 2014 are now PWD, excluding the uniformed and enforcement bodies (Economic Planning Unit, 2015).

During the Tenth Plan, rural road coverage expanded by $11.7 \%$ from 45,905 kilometres in 2009 to 51,262 kilometres in 2014. In Sarawak, 250 kilometres of ex-logging roads were upgraded to provide accessibility to 31,512 people in underserved rural areas. Rural electricity coverage reached $97.6 \%$ and water supply reached 93.8\%. 188,270 water tanks were provided to supply clean water to 251,200 households in remote areas in Sabah and Sarawak. 1,122 telecentres were established to enhance digital inclusion and inculcate a culture of innovation and creativity. In addition, 5,737 villages were connected through the Kampung Tanpa Wayar programme and 971 telecommunication towers constructed. The increased access to the Internet enabled rural and suburban communities to acquire new skills and knowledge, and generate alternative sources of income (Economic Planning Unit, 2015).

Seventy-seven Mobile Community Transformation Centre (Mobile CTC) programmes involving more than 50 government and private agencies were organised, benefiting almost 135,000 people. These Mobile CTC programmes are a key touch point bringing government services to the rural community, especially in remote areas. Activities such as sports, community services, and social gatherings were also organised in parallel to bring people together and promote unity. The Mobile CTCs also provide a platform for the government to channel assistance directly to the target groups, including micro-credit facilities. Financial inclusion has also increased with 4,351 Bank Simpanan Nasional (BSN) agents appointed throughout the nation to provide banking services, including savings and withdrawal transactions, as well as bill payment (Economic Planning Unit, 2015).

The development of the Bumiputera Economic Community (BEC) involved specific initiatives for Bumiputera companies based on their business needs. Entrepreneurs were assisted in terms of financing, support services, and capacity building. Over RM9 billion in financial assistance was provided to more than 414,000 Bumiputera businesses. Loans of RM8.6 billion benefited 413,278 micro and small businesses such as AIM entrepreneurs earning more than RM3,500, an increase from 27,770 in 2010 to 128,450 in 2014 and TEKUN Nasional stated that $32.7 \%$ of entrepreneurs recorded an increase in revenue of 50-150\% in 2013. Besides, financial assistance totalling RM495.2 million to 760 Bumiputera small and medium enterprises (SMEs) in the development and growth stage, by Malaysia Technology Development Corporation (MTDC), Malaysia Venture Capital Management Berhad, Malaysia Debt Ventures Bhd, and Multimedia Development Corporation (MDeC) (Economic Planning Unit, 2015).

Appropriate facilities such as hostel, transport, and financial aid will continue to be provided to students in rural and remote areas to enable them to complete primary and secondary education. The K9 School will be expanded to increase student enrolment, particularly among the Orang Asli in Peninsular Malaysia, and those living in the rural and remote areas in Sabah and Sarawak. Special attention will also be given to address the needs of children from identified segments of disadvantaged groups, including children from Malay households in traditional villages, Indians from dislocated estates and urban areas, as well as Chinese from new villages. Special awareness programmes on the importance of education will be conducted for schoolchildren and their parents to inspire a mindset change (Economic Planning Unit, 2015).

Accessibility to higher education and skills training among students from B40 households will be enhanced through special programmes. Institutions of higher learning and skills training institutes will be encouraged to provide more places for these students through preferential entry qualification criteria and enrolment quota. This will be complemented with the provision of financial aid. Special consideration will be given to potential students from Orang Asli communities in Peninsular Malaysia, and those living in rural and remote areas in Sabah and Sarawak (Economic Planning Unit, 2015).

B40 households in rural areas who are self-employed such as farmers, fishermen, and smallholders will be encouraged to adopt modern technology to increase productivity and income. Structured modular programmes focusing on modern farming techniques and good agricultural practices will be intensified. Amalgamation of land and merging of small-scale business activities will also be encouraged to benefit from economies of scale. The role of relevant agencies such as Federal Agriculture Marketing Authority (FAMA), Malaysian Agricultural Research and Development Institute (MARDI), and Fisheries Development Authority of Malaysia (LKIM) will be streamlined to provide relevant services and facilitation to these households (Economic Planning Unit, 2015).

SME Corp will coordinate the development of the SMEs owned by B40 households. Collaboration among agencies providing entrepreneurship support programmes to micro-, small- and medium-scale entrepreneurs in urban and rural areas such as SME Corp, TEKUN Nasional and AIM will be strengthened to provide integrated assistance 
and reduce overlapping activities. Broader business development opportunities will also be provided by these agencies. Microenterprises will also be linked to banking and financial institutions for easier access to funding. Initiatives will include establishing smart partnerships with research and development (R\&D) institutions to assist the SMEs to improve product quality, enhance compliance to standards and increase market access. In this regard, SME Corp will introduce integrated entrepreneurship development packages which will cover start-up till market product placement activities. In addition, Urban Transformation Centre (UTC) and Rural Transformation Centre (RTC) facilities will be utilised to facilitate entrepreneur training programmes. To encourage rural entrepreneurship, an appropriate socio-economic environment will be established to facilitate local activities. The entrepreneurial orientation programme focused on stimulating local entrepreneurial talent and growth of indigenous companies will be introduced. This is critical to create jobs and add economic value to rural areas while retaining scarce resources within the community. It is important to sustain this effort so that the entrepreneurship culture is embedded within rural communities. Initiatives to enhance access to financing and entrepreneurship training, as well as the provision of advisory services, and business premises will be increased. These initiatives will enable the mobilisation of rural youths to be employed and participate in entrepreneurship activities to minimise migration to urban areas (Economic Planning Unit, 2015).

About twenty-six percent (26.3\%) of Malaysians or 7.92 million people live in rural areas across the nation, with varying levels of accessibility to sub-urban areas, infrastructure, social amenities and economic opportunities. Uplifting the wellbeing of rural communities continues to be a priority in the Eleventh Plan, in line with the objective of ensuring balanced growth across geographies. Five strategies will be delivered to achieve these outcomes during the Eleventh Plan:

Strategy C1: Extending provision of rural basic infrastructure by streamlining rural infrastructure planning and increasing the provision of road, water and electricity supply;

Strategy C2: Encouraging more private investment in rural areas by providing a more conducive business environment;

Strategy C3: Improving rural-urban linkages by improving connectivity and mobility as well as using ICT to strengthen the role of UTCs, RTCs and mini-RTCs;

Strategy C4: Expanding access to basic services by expanding the mobile community transformation centre programme, and extending banking services to rural areas; and

Strategy C5: Streamlining the delivery system by reviewing the role of Regional Development Authorities (RDAs).

In rural areas, are outlined several problems that could be typical there which include, surplus of labour force due to fewer jobs that are opened to the people living there. Most jobs are for unskilled worker (picking up palm oil fruit, rubber tree) with the wages and the nature of work is unattractive. Migration from rural areas to cities among higher qualification workers (diploma or degree holder) also happen because they are sometimes too choosy in picking a job or career. Problems of the labour force are the most serious and difficult to solve because they affect people with their skills, initiatives and opportunities. All of this could lead to depopulation and strong aging. Low labour productivity can be the reasons for lower income of the people in rural areas by means they have low prices of agricultural products. Besides, poor working and living conditions in the rural areas due to underdeveloped infrastructure and public services such as roads, transportation, water supply and sewerage, electrical and communications network. In addition, low quality of health and education can be the main reasons for depopulation and migration among people in rural areas (Surchev, 2009).

In many types of rural area, unemployment and under employment among young people have been a particular of causes for concern and a key issue in rural communities is the lack of employment opportunities and career choices for young people. Although many of the problems associated with unemployment that are faced by urban youth also apply to those living in rural areas, rural youth face an additional set of barriers which are linked to their spatial isolation and to the narrow range of opportunities which are available. For rural youth, some of the most effective bridges into the labour market such as education and training may be limited or inaccessible and opportunities to fulfil aspirations may be restricted (Cartmel \& Furlong, 2000).

\section{CONCLUSION}

More opportunities can be the solutions to these problems, investment in education and training is more important in many rural areas. Higher educational levels contribute to local economic development in several ways. First, a well- educated workforce facilitates the adoption of new ways of production of goods or providing services among local businesses. Second, prospective employers may view a well- educated local labour forces an asset when choosing among alternative locations for new establishment. Both factors could help improve a community's chance of attracting new businesses, particularly those businesses that require highly skilled employees. Finally, higher education levels are almost always tied to geographic clusters of certain key industries, which in some cases 
have generated major economic growth in rural areas ("Education as a Rural Development Strategy," 2005). Besides, in Turkey traditionally, education has been associated with the process of instructing young people in ways which form the mind and character necessary to become good citizens and employable workers. During the past 50 years, expansion of education has contributed to a fundamental transformation of OECD countries, including Turkey (Owings, Kaplan \& Pirim, 2012). Ogbu (n. d.) stated that one theory has influenced educational policies in the Third World and in the United States which states that education increases people's general mental capabilities and technical skills, thereby increasing their productive potential in labour force. He also stated that the theory of human capital that applied to developing nations asserts that the economic and social development of these countries would be facilitated if they invested more in educating their people (Ogbu, n.d.).

Klein stated that entrepreneurship is often conceived as innovation, creativity, the establishment of new organizations or activities, or novelty (Paull \& Sharma, 2013). Entrepreneurial development can often be a costeffective economic development strategy. Entrepreneurship can be a vehicle for leveraging existing community strengths and diversifying local economies, while also challenging existing business to be more efficient and innovative.

Lundu District is an administrative area under Kuching Division and is in the Northwest Division of Kuching, Sarawak near the border of the region West of Kalimantan, Indonesia. Lundu District's administrative area covers a total area of 1962.2 square kilometres. Malays, Iban, Bidayuh, Chinese, Salako and Rara are the people living in Lundu and Sematan. Lundu District is under administration and management of Lundu District Office as the District Officer, Tuan Awang Putrayusrie Bin Awang Redzuan who is the current coordinator for all development activities at district level. Lundu District Office plays an important role in ensuring development process in Lundu District as well as safeguarding both welfare and the interests of people in Lundu and Sematan. Among the main roles of Lundu District Office are planning, tracking and report on the development projects. Among the development projects that have been implemented are small rural projects worth RM 200,000 or less of these values but there are also some projects that have high values. The most notable development project for this district office is a Small Rural Project (MRP) related to the home help programme (PBR) for the poor who are in need and providing an assistance for home repairs for the poor. In addition, it is also able to help reduce the poor in Lundu District as most of those who receive it are from the recipient of $e$-Kasih help. E-Kasih assistance is an aid to help the poor which are in this area and some of them also receive $1 \mathrm{Azam}$ assistance which help the poor to enable them to generate income and change their standard of living ("Laman Web Majlis Daerah Lundu", 2018).

\section{REFERENCES}

Cartmel, F., \& Furlong, A. (2000). Youth unemployment in rural areas. Layerthorpe, York: Joseph Rowntree Foundation.

De Gennaro, B., \& Fantini, A. (n.d.). The concept of rurality and the rural-urban relationship as perceived by young people. Retrieved from https://pdfs.semanticscholar.org/3aad/f6297ef0613beb84e62cc857075f9c69 8ee7.p df.

Economic Planning Unit, Prime Minister's Department. (2015). Eleventh Malaysia Plan 2016-2020: Anchoring growth on people. Putrajaya, Malaysia: Percetakan Nasional Malaysia Berhad.

Laman Web Majlis Daerah Lundu. (2018). Retrieved from http://www.lundudc.sarawak.gov.my.

Ogbu, J. U. (n.d.). Investment in human capital: Education and development in Stockton, California, and Gwembe, Zambia. Retrieved from http://digitalassets.lib.berkeley.edu/anthpubs/ucb/text/kas063_064-011.pdf.

Owings, W. A., Kaplan, L. S., \& Pirim, Z. (2012). Education as an investment in Turkey's human capital: A work in progress. Eurasian Journal of Business and Economics, 5(10), 45-70.

Paull, M., \& Sharma, A. (2013). Entrepreneurship as a tool for rural development. Global Journal of Management and Business Studies, 3(3), 319-322.

Surchev, P. (2009). Rural areas-problems and opportunities for development. Trakia Journal of Sciences, 8(3), 234-239. 